\title{
CONSTRUCTION WASTE MANAGEMENT PERFORMANCE IN GREEN BUILDING: CONTEXTUALISING LEED IN CHINA
}

\author{
Zhikang Bao ${ }^{1, *}$, Weisheng Lu ${ }^{1}$, Bin Chi ${ }^{1}$, and Jianli Hao ${ }^{2}$ \\ ${ }^{1}$ Department of Real Estate and Construction, Faculty of Architecture, University of Hong Kong, Pokfulam, Hong Kong \\ ${ }^{2}$ Department of Civil Engineering, Xi'an Jiaotong-Liverpool University, Suzhou, China
}

Article Info:

Received:

12 July 2019

Revised:

14 February 2020

Accepted:

25 March 2020

Available online:

24 July 2020

Keywords:

Construction waste management

Green building

LEED

PEST analysis

China

\section{ABSTRACT}

Construction waste issues have raised considerable concern in recent decades. Green building (GB) has been adopted around the globe as a strategy to curtail building-related environmental issues, including construction waste. Particularly in China, with the soaring construction activities tied to urbanization and urban regeneration, massive construction waste has been generated, imposing tremendous pressure on the industry and beyond. China is also vigorously pursuing a national GB strategy, but its effects on construction waste management (CWM) are yet to be confirmed. This paper evaluates CWM performance in GB by putting the dyads into China's particular Political, Economic, Social, and Technical (PEST) context. By analysing a total of 310 LEED (Leadership in Energy and Environmental Design) accredited GB projects in China, it is surprisingly discovered that GB does not prominently improve CWM. The paper goes further to understand the causes of the mediocre CWM performance, by conducting ten semi-structured interviews with GB and CWM practitioners in China. Finally, a comprehensive PEST analysis is conducted to discuss the situation in the context of China. Factors such as (a) incomplete CWM regulations in China, (b) lack of economic incentives, (c) lacklustre awareness about CWM, and (d) lack of advanced technologies, caused the CWM performance in GB. Based on the PEST analyses, some targeted strategies are also recommended. This study is of benefits to both researchers and practitioners in the GB industry.

\section{INTRODUCTION}

Construction plays a pivotal role in materializing the built environment and maintaining the national economy in China, revealed from its prodigious portion contributing to its Gross Domestic Product (GDP) with a contribution of consistently over $6 \%$ in recent years (NBS, 2019). However, construction activity by nature is hostile to the natural environment. It can lead to a series of negative impacts, including land depletion and deterioration, energy consumption, solid waste generation, dust and gas emissions, noise pollution, and consumption of non-renewable natural resources (Shen et al., 2007; Lu and Yuan, 2011; Yang et al., 2019; Yang et al., 2020), which have been frequently witnessed in the past decades in China. Amongst the contributions leading to environmental degradation, the solid waste generated from construction activities has plagued China for decades.

The solid waste arising from construction, renovation, and demolition activities is called construction waste, or sometimes, called construction and demolition (C\&D) waste (Kofoworola and Gheewala, 2009; Wu et al., 2017). In recent years, a considerable amount of construction waste has been generated in China due to the mounting construction activities tied to urbanization and urban regeneration. C\&D waste has incurred negative social-economic and environmental effects (Ye et al., 2012; Wu et al., 2019). The world generates over 10 billion tons of construction waste every year and about one quarter of the total waste is generated in China, reaching up to 2.3 billion tons (Lu et al., 2016; Ajayi et al., 2016; Zheng et al., 2017). Lu et al. (2016) estimated that approximately 1.13 billion tons of C\&D materials were generated in China during 2014. Conventionally, the disposal methods for construction waste are landfill and incineration, which not only considerably occupy valuable land resource but also causes environmental deterioration. Therefore, how to tackle construction waste problems, termed as construction waste management (CWM), has become a discipline in its own right. In the past decades, CWM has been receiving increasing attention in China due to the growing awareness of embracing sustainability. To address the issues arising from construction waste needs various grand, systematic initiatives. Among them, a promising initiative is to embrace the green build- 
ing movement in China.

Here, green building (GB) refers to an environmentally responsible and resource-efficient structure or site throughout its lifecycle (EPA, 2016). Amidst the global trend of achieving sustainable development, GB has been elevated to the top of many construction-related institutions, including China. An array of governments, professional institutions, and independent organizations have developed and launched green building rating systems (GBRSs) to outline GB standards and label certifications. There are eight categories of project performance defining the assessment criteria of most prevailing GBRSs, covering project management, site, energy, water, materials, emission and storage of hazardous materials, and indoor environment quality (Gou and Lau, 2014; Wu and Low, 2010). CWM, as a pivot indicating the degree of sustainability, has also been formulated in most prevailing GBRSs. It has been found that credits aiming for CWM are typically under the "Materials" category, comprising $8-12 \%$ of all the attainable credits in a GBRS (Tam et al., 2004; Lu et al., 2016). Substantial studies have been undertaken to examine the effects of GB on carbon emission, energy saving, occupant comfort, and property market price (Shuai et al., 2018; Castleton et al., 2010; Zhang and Altan, 2011; Fuerst and McAllister, 2011). Nonetheless, rather limited studies have explored the effectiveness of GB on CWM, even though CWM also plays a critical indicator of sustainability.

Hence, this study aims to evaluate the effects of GB on CWM in China, and then understand the causes of the effects by conducting a series of semi-structured interviews and a comprehensive political, economic, social, and technological (PEST) analysis. According to the PEST identified, a series of targeted strategies are also recommended to improve the CWM performance. This study will focus on the GBRS of U.S.-developed Leadership in Energy and Environmental Design (LEED) because it is the most prevailing and widespread GBRS globally. A large number of GB projects in China have also been accredited by LEED. The deliverables of this study are not only beneficial to researchers and practitioners in the GB industry, but also provide a good reference for exploring whether GB can be used as a tool to improve the CWM performance in China.

\section{LITERATURE REVIEW}

\subsection{Green building movement}

The concept of GB can be traced back to 1960s when the energy crisis and environmental pollutions concerns were increasingly anabatic due to the over-exploitation and overuse of fossil energy (Kibert, 2004). In the 1980s, with the increasing embracement of sustainability in various industries, the call for sustainability in the construction industry has become extremely strong with the consciousness of the building industry as a predominant contributor to energy consumption and environmental pollution (Lu and Tam, 2013). Under this background, UK created the first GBRS in the world, BREEAM (Building Research Establishment's Environmental Assessment Method), which represents a milestone of the world GB movement (Cohen et al., 1998). Afterward, the GB movement has entered the track of rapid development (Shen et al., 2012).

Nowadays, GB, also known as sustainable building, refers to a practice of creating structures and using processes that are environmentally responsible and energy efficient throughout a building's life cycle from planning, design, construction, operation, maintenance, and deconstruction (EPA, 2016). Green buildings are created to relieve the adverse impacts of the built environment on both human and natural environment (EPA, 2016). In recent decades, GB development has witnessed an unprecedented surge, and numerous GBRSs have been issued by an array of governments, professional bodies, and independent organizations to pioneer sustainability of the construction industry (Chi et al., 2020). GBRSs are tools to evaluate a building's performance in conformity to a series of criteria, such as site, energy, water, air, and materials (Wu and Low, 2010). Usually, GBRSs are created by a panel of experts and stakeholders (Gou and Lau, 2014). A study conducted by Vierra (2014) estimated that there are more than 600 GBRSs globally. Amongst them, LEED developed by the U.S. is the most widely spread GBRS. According to USGBC (U.S. Green Building Council) (2019), there have been more than 94,000 LEED-certified projects in 167 countries and territories globally.

In terms of the GB movement in China, the emergence of GB is later than the west until 2005 when the first "international green building conference" was held in Beijing. After one year, in 2006, the Chinese national GBRS, Green Building Evaluation Label (GBEL) was formally issued, which significantly catalysed the GB movement in China. Even though the inception of GB in China is later, the permeation of it is incredibly in-depth into the market. It is ambitious of the Chinese government that by $2020,50 \%$ of new residential buildings will be certified by GBRSs according to its "Construction Industry $13^{\text {th }}$ Five-Year Plan" (Zhang and Kang, 2018). Amongst the GBRSs prevailing in the Chinese market, LEED possesses the leading position among the clients despite the fact of the existence of its national GBRS, GBEL. It is announced by USGBC (2018) that there have been more than 1,211 LEED-certified projects (47.16 million $\mathrm{m}^{2}$ GFA) until 2017, second only to the U.S. globally. That is why LEED in China is the research focus of this study.

\subsection{Construction waste management}

Construction waste, sometimes termed as construction and demolition waste (C\&D waste), refers to the solid waste resulting from any construction activities, such as new construction, renovation, and demolition (Roche and Hegarty, 2006; Lu et al., 2019). Construction waste can be generally classified into two generic portions, inert materials and non-inert waste depending on whether it has stable chemical properties (EPD, 1998). Inert materials, such as soil, earth, slurry, rocks and concrete accounts for the vast majority of the construction waste and are suitable to reuse and/or recycle for different purposes, e.g., road formation, land reclamation, and recycled aggregate. The non-inert waste mainly comprises bamboo, plastics, glass, wood, and paper, contaminates the surrounding environment significantly. Therefore, it is not considered for reuse 
and/or recycling, and it is normally disposed of at landfills (Poon, 2007). Landfilling not only gives rise to negative social-economic impact but also leads to environmental degradation due to anaerobic decay of the materials disposed of and thus the production of carbon dioxide, methane, and leachate (Lu et al., 2015). It also rapidly exhausts invaluable land resources.

In recent decades, vast amounts of construction waste have been generated, which has raised worldwide attention. The need to tackle the construction waste issues gradually fosters the emergence of a distinct discipline, termed as construction waste management (CWM). CWM

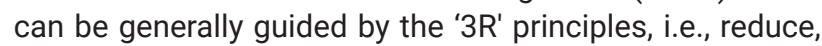
reuse, and recycle according to their desirability (Peng et al., 1997). The 3R's highest priority, the reduction has been examined extensively, and substantive measures have been proposed. Such measures generally involve either (1) adopting low waste technologies; (2) reducing waste by design; (3) raising practitioners' attitudes towards waste reduction; (4) developing an effective waste management system; or (5) reducing waste by government legislation ( $\mathrm{Lu}$ and Yuan, 2011). Reuse means using the same material in construction more than once, including using the material again for the same function (e.g. formwork in construction) (Ling and Leo, 2000) and new-life reuse for a new function (e.g. using the cut-corner steel bar for shelves; using the stony fraction for road base material) (Duran et al., 2006). Recycling is considered the final option before disposal. Through recycling, a variety of new materials can be made from construction waste (Bao et al., 2019).

Compared with other Western developed countries, construction waste issues in China are even worse. China is already the world's largest waste generator and by 2030 its volume of waste is projected to be double America's volume of municipal solid waste (MSW); nearly $40 \%$ of the MSW generated is construction waste, consuming about $40 \%$ of natural resources and energy (WEF, 2018; Wang et al., 2008). Nowadays, around three-quarters of Chinese cities are facing the dilemma known as "waste siege". The construction waste issues in China are even more grievous as a result of poor CWM performance (Bao and Lu, 2020). The reuse and recycling rate of construction waste in China is only $5 \%$ compared with that of $70 \%-95 \%$ in some developed countries (Huang et al., 2018). With the further urbanization and urban renewal in China, the construction waste issues would be even worse and thus, it is imperative for China to devise some effective strategies to tackle the construction waste issues. That is why this study aims to evaluate the effectiveness of GB on CWM to see whether GB can be applied as a strategy to tackle the construction waste issues in China.

\subsection{GBRS and CWM dyads}

Considering that CWM is pivotal in the process of fostering sustainability in the construction industry, some scholars have tried to explore the potential of GBRSs to tackle construction waste issues. For example, Lu et al. (2019) did a study trying to compare the CWM performance among the three GBRSs and unveiled that poor CWM performance is in common in the three GBRSs. Addi- tionally, Lu et al. (2018) analysed the effects of BEAM Plus, GBRS developed by Hong Kong, on CWM performance with big data analytics applied and the results indicate that CWM performance shows a notable reduction only in demolition projects. Chen et al. (2018) furthered the study of the nexus between BEAM Plus and CWM and discovered that BEAM Plus has a negligible influence on CWM performance. Furthermore, Wu et al. (2016) compared the CWM related items in the five GBRSs and uncovered that GBEL, Chinese national GBRS pays the most attention to the CWM problems, while GBI (Green Building Index), GBRS developed by Malaysia emphasizes the CWM the least. To conclude, even though there have been some studies trying to investigate the potential of GBRSs to tackle the CWM, minimal research, if any, has probed into the effectiveness of LEED specifically in China, although China is the largest construction market and LEED is the most widespread GBRS. This is the research gap this study intends to fill.

\section{RESEARCH METHODS}

This study adopts a mixed method, including three phases, i.e., archive analysis, semi-structured interview, and PEST analysis. These three phases are related and succeeded mutually, which are elaborated individually below. To help the readers better understand the research methods adopted in this study, a framework is made (see Figure 1).

\subsection{Archive analysis}

This study begins with a series of desktop archive analysis to examine how GB projects certified with LEED influence CWM. The version of LEED v2009 New Construction is selected for this study due to the fact that the number of projects certified under the most recent version, the amount of LEED v4 is still limited during the study period. The authors first analysed where the CWM-related credits are allocated in the LEED. It is found that the credits related to CWM in this rating system normally reside under the category of 'materials \& resources'. After finding out where the CWM-associated credits exist, the authors also identified the CWM-related credits by probing into the evaluation criteria by item by item. Afterward, a total of 310 GB projects accredited LEED including different certification levels in China has been sourced from the U.S. Green Building Council (GBC) in this study. By calculating and comparing the average rate of credits attained under the category of CWM and other performance categories, it is intuitional to discover how the GB affect CWM.

\subsection{Semi-structured interviews}

Following the archive analysis, the study conducted a series of semi-structured interviews to explore the reasons for the effect of GB on CWM (Wang et al., 2019). Therefore, a succession of semi-structured interviews was undertaken by collecting the qualitative data with LEED and CWM experts, consultants, researcher, project managers based in China. The detailed profile of the interviewees is shown in Table 1. In total, 10 experienced and professional in both LEED and CWM construction industry practitioners were 


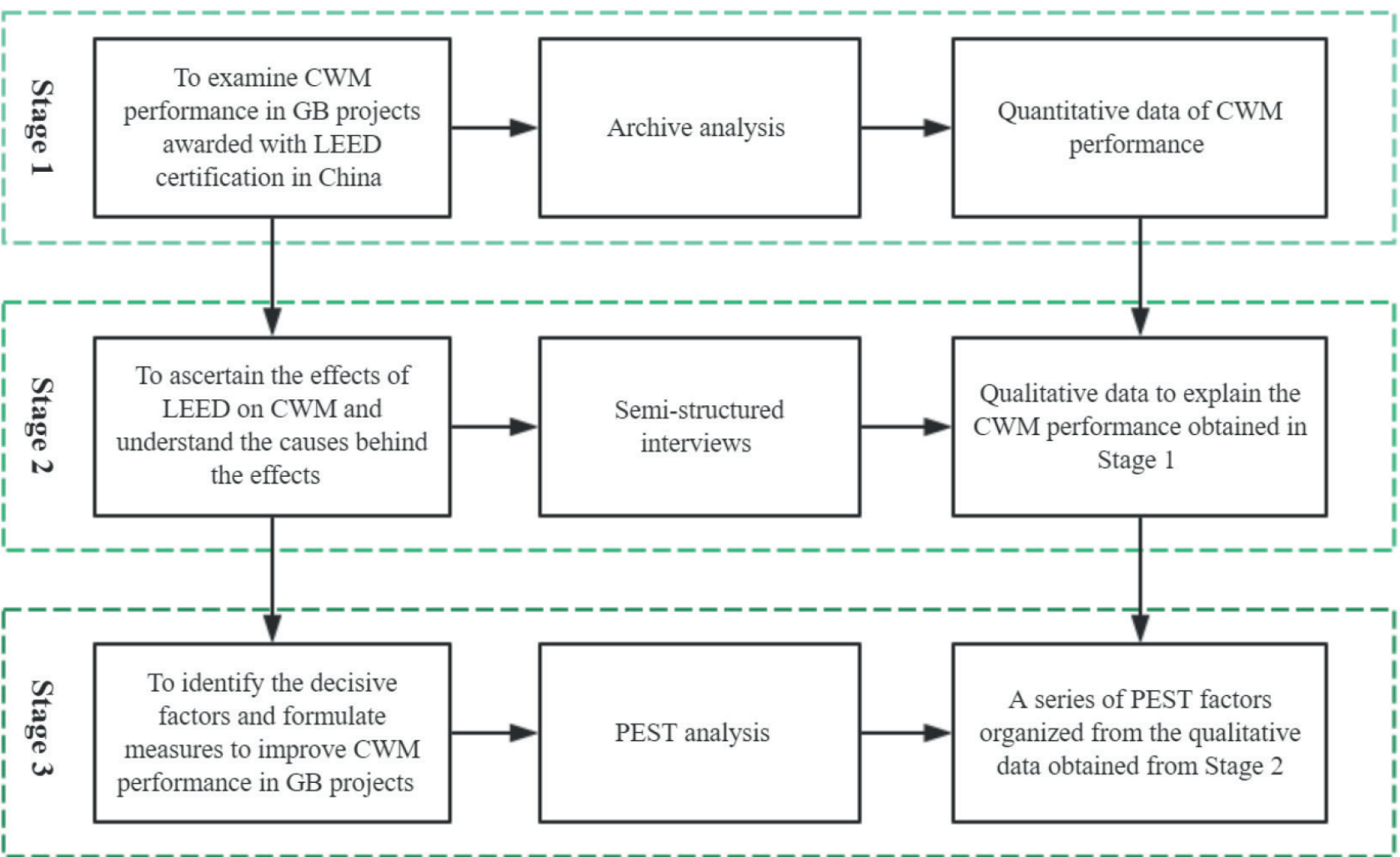

FIGURE 1: Framwork of research: objectives, methods, and corresponding deliverables.

interviewed. These interviewees, with deep industry experience, have been engaged in a great many GB projects awarded by LEED.

The interviews were started by asking some open-ended questions by eliciting the interviewee's overall opinions on the LEED itself in the context of China. Then the questions were extended to CWM in China, e.g.:

How is the CWM situation in China generally?

- What do you think is the cause of the CWM situation in China?

- In your opinion, is the current CWM-related credits allocation in the LEED rational enough to better improve the CWM performance in China?

Afterward, the questions were even more targeted at the specific item in the LEED and asked credit by credit, e.g.:

- Which credits are relatively harder to achieve?

- Why the credits are difficult to obtain?

- Based on your practical experience, is there any effective approach to deal with the corresponding difficulty?

For each of the interview, it lasted between one to two hours. The tape-recording was conducted for some of the interviews, while if the interviewee did not agree to the recording, a detailed note was taken accordingly. If some notes taken during the interviews were not clear, the tele- phone call was dialled with the interviewee to check, which ensures the validity of the data.

\subsection{PEST analysis}

By collecting the qualitative data from the semi-struc-

TABLE 1: Profile of the interviewees.

\begin{tabular}{|c|c|c|}
\hline No. & Role & $\begin{array}{l}\text { Relevant working } \\
\text { experience }\end{array}$ \\
\hline 1 & $\begin{array}{l}\text { GB expert in an architecture firm, architect, } \\
\text { LEED AP }\end{array}$ & $>12$ years \\
\hline 2 & $\begin{array}{l}\text { GB consultant in a world-class engineering } \\
\text { consultancy firm, LEED AP }\end{array}$ & $>8$ years \\
\hline 3 & $\begin{array}{l}\text { GB consultant in a local GB consultancy firm, } \\
\text { LEED AP }\end{array}$ & $>5$ years \\
\hline 4 & $\begin{array}{l}\text { GB consultant in a national architecture } \\
\text { institute, LEED AP }\end{array}$ & $>6$ years \\
\hline 5 & $\begin{array}{l}\text { GB consultant in a regional comprehensive } \\
\text { design firm, engineer }\end{array}$ & $>15$ years \\
\hline 6 & $\begin{array}{l}\text { GB expert in a regional architecture institute, } \\
\text { LEED AP, engineer }\end{array}$ & $>15$ years \\
\hline 7 & $\begin{array}{l}\text { Researcher in a regional architecture } \\
\text { institute }\end{array}$ & $>5$ years \\
\hline 8 & $\begin{array}{l}\text { GB expert in a regional GB council, architect, } \\
\text { LEED AP }\end{array}$ & $>8$ years \\
\hline 9 & $\begin{array}{l}\text { Project manager in a state-owned construc- } \\
\text { tion firm, engineer }\end{array}$ & $>20$ years \\
\hline 10 & $\begin{array}{l}\text { Director in a real estate development firm, } \\
\text { engineer }\end{array}$ & $>12$ years \\
\hline
\end{tabular}


tured interviews, a comprehensive PEST analysis was conducted. The PEST refers to four factors, political, economic, social, and technological. It is a powerful and widely used tool for understanding strategic risk, identifying the change and the effects of the external macro environment (Sammut-Bonnici and Galea, 2015). PEST analysis has two functions. The first is to identify the external environment where the company or organization operates, while the other is to provide data and information to enable the company to predict situations and circumstances and formulate strategies (Yüksel, 2012). PEST was firstly developed to apply in the discipline of market research, but in recent years, it has been widely applied across the disciplines due to the awareness of its significance. Adapting the PEST analysis into this study, it can assess how GB affect the CWM in the context of China from four external factors, political, economic, social, and technological. The results of the analysis can inform the practitioners for reference to formulate the strategies to improve CWM in the future.

\section{RESULTS AND FINDINGS}

\subsection{Archive analysis}

From the archive analysis, Table 2 shows the credits allocated to CWM in the LEED. The study identified CWM associated credits by going through all the criteria item by item. The LEED version 2009 for New Construction includes seven aspects of assessment, i.e., sustainable sites, water efficiency, energy \& atmosphere, materials \& resources, indoor environmental quality, innovation, and regional priority credits. It is examined that pertinent credits relating to CWM lie on the performance category of materials \& resources as listed in Table 1. The materials $\&$ resources category receives 14 credits out of total 110 credits, in the interim, 11 points can be attained by CWM. The attainable point(s) of each CWM related item, as well as its relative weight in the overall grade, were presented in the last two columns of the table, from where all CWM associated points account for $10 \%$ of the total LEED score. It can also be perceived that this rating system allocates dissimilar emphasis on different aspects of CWM performance when devising the crediting mechanism.

This study has sourced the scoring data of all the 310 projects (as of 30 April 2019) certified for green building certification as LEED (see Table 3 ) in China. Table 3 shows the detailed credit distributions of LEED-certified projects at different levels of certification. It is noticed that GB projects obtained low scores in the category of materials \& resources (MR) where CWM related items are allocated. Based on the identification shown in Table 2, the authors created one more column depicting how CWM is performed in real-life LEED evaluation shown in the last column. The analysis so far indicates that less than $32 \%$ of the total applicable credits in CWM are attained, which are relatively lower in each level of certification. It can be induced that the designated performance of enhancing CWM via LEED has largely unattained. Furthermore, the detailed scores of each CWM-associated credit in the LEED-accredited buildings are elaborated in Table 4. It would be intriguing and necessary to keep digging the cause of this anomaly.

TABLE 2: CWM related credits in the LEED.

\begin{tabular}{|c|c|c|c|c|c|c|}
\hline \multicolumn{3}{|c|}{ Overall assessment framework } & \multicolumn{4}{|c|}{ CWM related credits } \\
\hline \multicolumn{2}{|r|}{$\begin{array}{l}\text { Performance } \\
\text { category }\end{array}$} & \multirow{2}{*}{$\begin{array}{c}\begin{array}{c}\text { Attainable } \\
\text { points }\end{array} \\
26\end{array}$} & \multicolumn{2}{|r|}{ Credit item } & \multirow{2}{*}{$\begin{array}{c}\text { Attainable } \\
\text { points }\end{array}$} & \multirow{2}{*}{$\begin{array}{c}\begin{array}{c}\text { Attainable rate in } \\
\text { overall grade }\end{array} \\
2.73 \%\end{array}$} \\
\hline 1 & sustainable sites (SS) & & MR1.1 & $\begin{array}{l}\text { Building reuse - Maintain existing } \\
\text { walls, floors, and roof }\end{array}$ & & \\
\hline 2 & water efficiency (WE) & 10 & MR1.2 & $\begin{array}{l}\text { Building reuse - Maintain existing } \\
\text { interior non-structural elements }\end{array}$ & 1 & $0.91 \%$ \\
\hline 3 & energy \& atmosphere (EA) & 35 & MR2 & Construction waste management & 2 & $1.82 \%$ \\
\hline 4 & materials \& resources (MR) & 14 & MR3 & Materials reuse & 2 & $1.82 \%$ \\
\hline 5 & indoor environmental quality (IEQ) & 15 & MR4 & Recycled content & 2 & $1.82 \%$ \\
\hline 6 & innovation in design & 6 & MR6 & Rapidly renewable materials & 1 & $0.91 \%$ \\
\hline \multirow[t]{2}{*}{7} & regional priority credits & 4 & & & & \\
\hline & Total & 110 & & & 11 & $10 \%$ \\
\hline
\end{tabular}

TABLE 3: The credits distribution of LEED-certified projects in China.

\begin{tabular}{|c|c|c|c|c|c|c|c|c|c|c|}
\hline $\begin{array}{l}\text { Certifica- } \\
\text { tion Level }\end{array}$ & $\begin{array}{c}\text { No. of } \\
\text { projects }\end{array}$ & $\begin{array}{c}\text { Average } \\
\text { Overall Grade }\end{array}$ & SS (\%) & WE (\%) & EA (\%) & MR (\%) & IEQ (\%) & ID & $\mathrm{RP}$ & CWM (\%) \\
\hline Platinum & 45 & 82.11 & 82.56 & 95.56 & 74.48 & 44.29 & 42.13 & 5.16 & 3.98 & 37.58 \\
\hline Gold & 147 & 64.64 & 75.20 & 91.09 & 37.84 & 39.94 & 36.17 & 4.63 & 3.90 & 32.53 \\
\hline Silver & 89 & 54.16 & 68.41 & 77.30 & 23.18 & 37.00 & 31.95 & 4.27 & 3.65 & 28.91 \\
\hline Certified & 29 & 45.07 & 66.31 & 60.00 & 17.04 & 31.28 & 24.43 & 3.59 & 2.17 & 25.39 \\
\hline Average & - & - & 73.12 & 80.99 & 38.14 & 38.13 & 33.67 & - & - & 31.10 \\
\hline
\end{tabular}

Note: $S S=$ sustainable sites; $W E$ = water efficiency; $E A=$ energy \& atmosphere; $M R=$ materials \& resources; IEQ = indoor environmental quality; $I=$ innovation in design; $R P=$ regional priority

Data Source: Public data posted on the official website of the U.S. Green Building Council 
TABLE 4: The CWM related credits distribution of LEED-certified projects in China.

\begin{tabular}{|c|c|c|c|c|c|c|}
\hline Certification Level & MR1.1 (\%) & MR1.2 (\%) & MR2 (\%) & MR3 (\%) & MR4 (\%) & MR6 (\%) \\
\hline Platinum & 0 & 0 & 97.78 & 1.11 & 91.11 & 33.33 \\
\hline Gold & 2.72 & 0.68 & 78.91 & 0 & 78.91 & 1.36 \\
\hline Silver & 1.12 & 0 & 91.01 & 0 & 66.29 & 0 \\
\hline Certified & 2.3 & 0 & 84.48 & 1.72 & 50 & 0 \\
\hline Average & 1.54 & 0.17 & 88.05 & 0.71 & 71.58 & 8.67 \\
\hline
\end{tabular}

\subsection{The performance of CWM explained}

Apart from the quantitative data collected above, this study also conducted ten semi-structured interviews with $\mathrm{GB}$ and CWM experts and practitioners. A combination of the qualitative analysis and quantitative analysis can help understand the rationales, i.e., the causes behind the poor performance with respect to CWM in real practice and assessment.

4.2.1 MR1.1 Building reuse - Maintain existing walls, floors, and roof \& MR1.2 Building reuse - Maintain existing interior non-structural elements

These two credits are aimed to encourage developers to reuse the existing, previously occupied building components including structural and nonstructural elements embedded in the first two items respectively. According to the requirements, the thresholds are set as $55 \%$ and $50 \%$ for the percentage of salvaged portion correspondingly. It can be noticed that minimal buildings can earn these credits even for the platinum-certified projects. Regardless of the certification levels, the average percentages of the projects that attained the credits MR1.1 and MR1.2 are only $1.54 \%$ and $0.17 \%$ respectively. In total, there are only six projects thereof that attained the credits among total 310 cases. As informed by the interviewees, the majority of GB projects are new construction, especially in China. These two credits are more applicable to reconstruction projects, which are more commonly seen in some developed countries, such as U.S. As such, it is scarcely for the new building to triumph the thresholds devised in the system. Additionally, achieving these credits is heavily reliant on the plan of demolition works in great details. The loss of previous design documentation, the tight project schedule, as well as the time cost expenditure can be the hindrance to living up the ideal demolition works as per the high LEED's standards. In that case, many developers and GB consultants will lower the priority of these two credits.

\subsubsection{MR2 Construction waste management}

To reduce the amount of construction waste going to the landfill and incineration facilities, the evaluation criteria are highly dependent on the data and necessary supporting documents submitted by the project contractors, indicating the percentage of the waste is recycled or salvaged. As shown in Table 4, the average percentage of the projects under the four certification levels reaches up to $88.05 \%$. Although the data shows GB projects got the highest rate of points under this criterion, it reveals one issue derived from the interviews. In China, only a few cities launch their regional regulations to specify the waste disposal proce- dure appropriately, but they still do not specify the sensible way to calculate the amount of waste recycled or salvaged which LEED does demand. As reflected by interviewees, the documentation requested by LEED basically relies on the estimation by figuring the number of dumpers and contractors' experience. Due to the lack of verification mechanism in the LEED evaluation process, the data may be thus vague, which does not mirror the actual performance in the real-life projects.

\subsubsection{MR3 Materials reuse}

This credit requires to use salvaged, refurbished or reused materials, the sum of the cost for using such materials should be reaching at least $5 \%$ of the total value of projects materials usage. It is found that the credits are scored rarely with the average percentage calculated only $0.71 \%$ from Table 4. There are three major reasons for this phenomenon, according to the interviews. Firstly, the quality and durability of reusable/recycled materials are the primary concerns from project stakeholders. To this end, they are reluctant to undertake unnecessary risks arising from the quality of the recycled products. Secondly, both developers and clients are unenthusiastic reusing old building materials, partially due to their traditional Chinese mindset, fond of the new and tired of the old. Due to this mindset, the adoption of recycled products is bound to affect the selling price of the projects and then the profitability of the stakeholders, particularly for some commercial and residential projects under the background of the current increasingly heated real estate market in China. Thirdly, the cost savings for applying the criteria might not considerably economize the project cost, since the selection of qualified recycled materials can increase the extra labor cost and time cost and may not be able to perform price soar of the property to be sold. In that case, this credit may not be a good candidate for scoring.

\subsubsection{MR4 Recycled content}

As reflected from Table 4, the average percentage of the projects that attained the credit MR4 is $71.58 \%$, which manifests that the majority of projects achieve the requirement of employing building products incorporated with recycled content, thereby decreasing the usage of natural virgin materials. As mentioned before, the validation of such credit depends on the evidence provided by the project developer/applicant. To obtain the credit, the developer or contractor should collect corresponding proper documentation to prove the proportion of recycled component reaches the thresholds from product suppliers. In the current market, there appears peculiar paucity of building materials origi- 
nally labeled with recycled content value within a material. Therefore, the contractors should re-identify eligible material suppliers, or provide a template of document for material suppliers to fill in the information that LEED requests. However, there is no standard operating procedure of data collection to ensure the authenticity of the information. As reflected by interviewees, making sure the authenticity of documentation is still the loopholes in the GB evaluation process. Some interviewees even admitted that the situation of the data fabrication to attain the credit is not uncommon in China.

\subsubsection{MR6 Rapidly renewable materials}

The average percentage of the projects attaining this credit is calculated as $8.67 \%$ from Table 4 . There appears to be a scarcity of GB projects that earned this credit because there are limited options for the materials specified in the requirement. According to the potential strategies mentioned in the indicator, it is suggested to consider using materials such as bamboo, wool, cotton insulation, linoleum, wheatboard, strawboard, and cork. Through interviews, the most commonly used types of rapidly renewable materials are bamboo and wood. For ordinary buildings, it is improbable to install these kinds of materials accounting for $2.5 \%$ of the total cost of building materials used in the whole project. Therefore, only some pilot demonstration projects that aim to achieve the big-league performance of LEED certification are planning to employ these kinds of certain materials in the very beginning usually at the stages like design or selection of suppliers, so as to get to the credit. Because of this condition, only platinum/gold-certified projects scored the point.

\subsection{PEST analysis}

From the results obtained from archive analysis and semi-structured interviews, CWM-related credits attained in the LEED-accredited projects in China were the lowest compared with other performance categories, inducing GB does not have distinct effects on improving regular CWM performance in China. A PEST analysis was conducted to analyze further and understand certain situations that China would face when promoting CWM in further ascension ahead. Four external perspectives (political, economic, social, and technological) are elaborated individually below (see Table 5).

\subsubsection{Political dimension}

Poor CWM performance in the GB projects can be attributed to the incomplete CWM regulations in China concerning the political dimension. Very few cities, like Beijing, Shanghai, and Shenzhen, have issued their regional CWM related regulations. A vast majority of cities still do not have any regulation to stipulate CWM issues. Even for the cities like Beijing, Shanghai, and Shenzhen, the regulations are far from complete compared with western countries and other developed economies. The current regulations are just enough to improve construction waste treatment at a very general stage. As a consequence, in terms of a specific situation, the regulations are difficult to follow. As echoed with Yuan (2013), comprehensive regulations could form a concrete basis to implement CWM. Nevertheless, the neighbors of (Mainland) China, e.g., Japan and Hong Kong, where the relatively mature and all-around CWM related political mechanism is implemented for addressing construction waste issues, and thereof have yielded notable effects on CWM. From the view of the political system, the primary endeavor is to formulate a series of systematic CWM related regulations at both national and regional levels. Besides, more efforts can be input in China to learn a well-rounded CWM system and practical experience from advanced countries/regions.

\subsubsection{Economic dimension}

In terms of the economic dimension, the lack of financial incentive gives rise to the subpar CWM performance in the GB projects. To have a better CWM performance in the GB projects, the cost imposed would be increased in various aspects. As mentioned by many interviewees, to obtain more CWM-related credits in the LEED-accredited projects, it is required to have efficient management on site and extra manpower for CWM, e.g., on-site sorting, which will surely increase the cost. Additionally, to obtain some credits, such as MR.3, it requires to use the recycled materials to diminish the consumption of virgin resources. However, the market for recycled building products in China is still in its infancy. The price of recycled building materials is even higher than virgin/ordinary materials, which economically hinders the stakeholders from adopting recycled materials. It makes sense that the environment is generally in the lower priority compared with the cost, quality, duration, and safety in the Chinese construction industry

TABLE 5: Summary of PEST analysis.

\begin{tabular}{|c|c|}
\hline PEST dimensions & Specific factors \\
\hline Political dimension (P) & $\begin{array}{l}\text { P1: limited regulatory enforcement on CWM in a handful of cities; } \\
\text { P2: imperfect CWM-relatad political system by the national and regional authorities; } \\
\text { P3: inadequate political support in promoting the adoption of recycled construction materials. }\end{array}$ \\
\hline Economic dimension (E) & $\begin{array}{l}\text { E1: addtional investment / cost in CWM (e.g. labor cost, on-site sorting); } \\
\text { E2: premature market for construction waste recycling industry; } \\
\text { E3: lack of economic motivation in promoting the adoption of recycled construction materials. }\end{array}$ \\
\hline Social dimension (S) & $\begin{array}{l}\text { S1: weak public awareness about developing better CWM; } \\
\text { S2: excessive worries on recycled construction materials from project stakeholers; } \\
\text { S3: undertrained on-site workers. }\end{array}$ \\
\hline Technological dimension $(T)$ & $\begin{array}{l}\text { T1: lack of core competente on recycled construction materials manufacture; } \\
\text { T2: deficient information and tools to implement proper demolition / deconstruction; } \\
\text { T3: insufficient funds for supporting research in field of CWM. }\end{array}$ \\
\hline
\end{tabular}


(Shen et al., 2006). Therefore, some strategies could be formulated from an economic perspective. For example, the government can provide direct financial incentives if the stakeholders use recycled materials to a certain level in the projects.

\subsubsection{Social dimension}

Considering the social dimension, a relatively low level of stakeholders' awareness about CWM in China results in the poor CWM performance in these projects. The contractors are reluctant to conduct CWM because, in the traditional Chinese construction industry, more concerns have been given to cost, quality, duration, and safety instead of the environment. For instance, on-site sorting is regarded as an effective approach for dealing with construction and demolition waste. However, in the real practice, the waste generated is usually divided into "can be sold", e.g., steel, metallic materials; and the remaining "cannot be sold" waste is muddled up together, then going to landfills without being separated. Moreover, generally in China, the on-site workers are not well educated, which causes their awareness on CWM is very low if there is not enough training provided for them. The behaviors of workers may directly impact the effectiveness of CWM in the execution. Therefore, the targeted strategy from the social perspective is that the government should provide a series of training courses for construction industry practitioners to enhance their awareness about the environment, as well as launch certain award as an incentive for stakeholders to actively involved and perform in CWM-associated events, so as to arouse public consciousness.

\subsubsection{Technological dimension}

Regarding the technological dimension, the interviewees stated that the current technology in China is still not advanced enough to support to have a better CWM performance. Some interviewees explained that most equipment in China to produce recycled construction waste materials is imported from western countries, significantly increasing the cost of recycled materials in the market. In turn, higher price hinders the stakeholders from using it in the projects. The above challenges have been largely responsible for the immature market for construction waste recycling, which will eventually affect the effectiveness of CWM performance. Additionally, there appears no specific and clear standard concerning the demolition or deconstruction work where a significant amount of waste generated. Demolition wastes are heterogeneous mixtures of building and decoration materials that are usually contaminated with lots of chemical components. As reflected by interviewees, a proper sequence and approach of demolition may primarily simplify the treatment of waste at source. Starting from this point, the proposed strategy is that the government should invest a considerable amount of funds to support the CWM related research, research and development (R\&D) in the fields of construction and demolition waste minimization, construction waste treatment guidelines, lean construction, prefabricated building, recycled building materials, sharing or trading of construction waste.

\section{DISCUSSION AND RECOMMENDATION}

Based on the results from PEST analysis as summarized in Table 5, some targeted recommendations have been proposed in accordance with the political, economic, social, and technological dimensions, which are elaborated individually below.

\subsection{Political dimension}

A well-developed CWM regulatory system with a well-defined hierarchy from national to regional should be established and emphasized in more cities as currently, only limited cities have formulated the CWM-related regulations. Also, the regulations formulated should be as detailed as possible so that they are straightforward to follow and enforce. Additionally, the conflicts of the regulations at the national and regional level should be avoided. Finally, once the CWM regulatory system has been enacted, the enforcement should be strictly executed.

\subsection{Economic dimension}

In the economic dimension, a mature construction waste recycling market should be cultivated, which can also provide some financial incentives for stakeholders to conduct the CWM behaviors, e.g., on-site sorting, partially if not fully covering their additional cost. Additionally, the government, either regional or national can allocate a specific fund to promote the adoption of recycled construction materials in construction, for example, different levels of subsidies can be set when different percentages of recycled construction materials are adopted in construction.

\subsection{Social dimension}

In terms of the social dimension, the government should use various public media tools to raise awareness of the public about the importance of CWM, such as newspapers and television programs. Moreover, the government can provide regular training courses for the practitioners involved in the CWM, including architects, engineers, contractors, and workers. Through the proper training, on-site workers can have better knowledge and skills on how to achieve better CWM performance and excessive worries on recycled construction materials from stakeholders can also be relieved or even eliminated.

\subsection{Technological dimension}

Regarding the technological dimension, the government should provide more funds to support the research of CWM in different manners. For example, the proper techniques for conducting demolition activities can reduce construction waste most in different situations. Moreover, the various equipment to achieve better CWM performance, such as on-site sorting equipment and the equipment for the storage of sorted construction waste should be developed as soon as possible so that the cost of stakeholders to use the equipment can be reduced. Additionally, the compilation of the standards of recycled construction materials, e.g., recycled aggregate for concrete is also of great importance. 


\section{CONCLUSION}

Construction waste issues have raised worldwide attention due to their negative social-economic and environmental effects. Particularly in some developing countries, massive construction activities have been undertaking to support their economic growth, leading to profuse construction waste generation. A promising strategy to address the issues is to promote green building. Some past studies have been conducted to investigate the potential of GBRSs to address CWM, but rather limited studies have probed into the effectiveness of LEED specifically focusing on China, hence calling for more studies to be conducted due to the extreme seriousness of CWM issues in China. To this end, this paper evaluates the effects of totally 310 GB projects accredited by LEED on CWM in China. From the archive analysis, it is discovered that CWM performance in these LEED certified GB projects is rather poor. The causes behind this phenomenon have been pointed out from item to item in the LEED based on the semi-structured interviews with GB and CWM experts and practitioners. Afterward, a comprehensive PEST analysis was conducted to probe into this phenomenon in the context of China.

Generally, the multiple causes, incomplete CWM regulations in China, lack of economic incentives of CWM, inadequate awareness concerning CWM and lack of advanced technologies from political, economic, social and technological (PEST) perspectives respectively hinder contractors and developers from achieving excellent CWM performance in practice. Finally, some strategies have also proposed to improve the CWM performance based on the PEST analyses. The study is beneficial to both researchers and practitioners in the GB industry. It also provides an important reference for exploring whether GB can be used as a tool to improve the CWM in China.

\section{ACKNOWLEDGEMENTS}

This research is supported by the General Research Fund (GRF) (Project No.: 17201917) from the Hong Kong Research Grants Council (RGC) and Public Policy Research (PPR) (Project No.: 2018.A8.078.18D) and Strategic PPR (Project Number: S2018.A8.010) Funding Schemes from the Policy Innovation and Co-ordination Office of the Government of the Hong Kong Special Administrative Region.

\section{REFERENCES}

Ajayi, S. O., Oyedele, L. O., Akinade, O. O., Bilal, M., Owolabi, H. A., Alaka, H. A., \& Kadiri, K. O. (2016). Reducing waste to landfill: A need for cultural change in the UK construction industry. Journal of Building Engineering, 5, 185-193.

Bao, Z., Lu, W., Chi, B., Yuan, H., \& Hao, J. (2019). Procurement innovation for a circular economy of construction and demolition waste: lessons learnt from Suzhou, China. Waste Management, 99, 12-21.

Bao, Z., \& Lu, W. (2020). Developing efficient circularity for construction and demolition waste management in fast emerging economies: Lessons learned from Shenzhen, China. Science of The Total Environment, 138264.

Castleton, H. F., Stovin, V., Beck, S. B., \& Davison, J. B. (2010). Green roofs; building energy savings and the potential for retrofit. Energy and buildings, 42(10), 1582-1591.

Chen, X., Lu, W., Xue, F., \& Xu, J. (2018). A cost-benefit analysis of green buildings with respect to construction waste minimization using big data in Hong Kong. Journal of Green Building, 13(4), 61-76.
Chi, B., Lu, W., Ye, M., Bao, Z., \& Zhang, X. (2020). Construction waste minimization in green building: A comparative analysis of LEEDNC 2009 certified projects in the US and China. Journal of Cleaner Production, 120749.

Cohen, S., Demeritt, D., Robinson, J., \& Rothman, D. (1998). Climate change and sustainable development: towards dialogue. Global Environmental Change, 8(4), 341-371.

Duran, X., Lenihan, H., \& O’Regan, B. (2006). A model for assessing the economic viability of construction and demolition waste recycling -the case of Ireland. Resources, Conservation and Recycling, 46(3), 302-320.

EPA. (2016). Green Building. Available at https://bit.ly/2SeDi83 [Access 9July 2019].

EPD. (1998). Monitoring of Solid Waste in Hong Kong. Environmental Protection Department, Hong Kong. Available from: https://bit. ly/2XvsJ1q [Access 9 July 2019].

Poon, C. S. (2007). Reducing construction waste. Waste Management, (12), 1715-1716.

Fuerst, F., \& McAllister, P. (2011). The impact of energy performance certificates on the rental and capital values of commercial property assets. Energy Policy, 39(10), 6608-6614.

Gou, Z., \& Lau, S. S.-Y. (2014). Contextualizing green building rating systems: Case study of Hong Kong. Habitat International, 44(C), 282-289. doi:10.1016/j.habitatint.2014.07.008.

Huang, B., Wang, X., Kua, H., Geng, Y., Bleischwitz, R., \& Ren, J. (2018). Construction and demolition waste management in China through the 3R principle. Resources, Conservation and Recycling, 129, 3644.

Kibert, C. J. (2004). Green buildings: an overview of progress. Journal of Land Use \& Environmental Law, 19(2), 491-502.

Kofoworola, O. F., \& Gheewala, S. H. (2009). Estimation of construction waste generation and management in Thailand. Waste Management, 29(2), 731-738.

Ling, Y. Y., \& Leo, K. C. (2000). Reusing timber formwork: importance of workmen's efficiency and attitude. Building and Environment, 35(2), 135-143.

Lu, W., \& Tam, V. W. (2013). Construction waste management policies and their effectiveness in Hong Kong: A longitudinal review. Renewable and sustainable energy reviews, 23, 214-223.

Lu, W., \& Yuan, H. (2011). A framework for understanding waste management studies in construction. Waste Management, 31(6).

Lu, W., Chen, X., Peng, Y., \& Liu, X. (2018). The effects of green building on construction waste minimization: Triangulating 'big data' with 'thick data'. Waste management, 79, 142-152.

Lu, W., Chen, X., Peng, Y., \& Shen, L. (2015). Benchmarking construction waste management performance using big data. Resources, Conservation and Recycling, 105, 49-58.

Lu, W., Chi, B., Bao, Z., \& Zetkulic, A. (2019). Evaluating the effects of green building on construction waste management: A comparative study of three green building rating systems. Building and Environment, 155, 247-256.

Lu, W., Webster, C., Peng Y., Chen, X., \& Zhang, X.L. (2016). Estimating and calibrating the amount of building-related construction and demolition waste in urban China. International Journal of Construction Management, 17(1), 13-24.

NBS (National Bureau of Statistics of China) (2019). Annual national economy summary, Beijing Statistics, Beijing.

Peng, C. L., Scorpio, D. E., \& Kibert, C. J. (1997). Strategies for successful construction and demolition waste recycling operations. Construction Management \& Economics, 15(1), 49-58.

Roche, T. D., \& Hegarty, S. (2006). Best practice guidelines on the preparation of waste management plans for construction and demolition projects. Department of the Environment, Community and Local Government: Dublin, Ireland.

Sammut-Bonnici, T., \& Galea, D. (2015). PEST analysis. Wiley Encyclopedia of management, $1-1$.

Shen, L., Hong, Y., \& Griffith, A. (2006). Improving environmental performance by means of empowerment of contractors. Management of environmental quality: an international journal, 17(3), 242-257.

Shen, L., Hao, J.L., Tam, V. W. Y., \& Yao, H. (2007). A checklist for assessing sustainability performance of construction projects. Journal of Civil Engineering Management, 13(4), 273-281.

Shen, L., Peng, Y., Zhang, X., \& Wu, Y. (2012). An alternative model for evaluating sustainable urbanization. Cities, 29(1), 32-39. 
Shuai, C., Chen, X., Wu, Y., Tan, Y., Zhang, Y., \& Shen, L. (2018). Identifying the key impact factors of carbon emission in China: Results from a largely expanded pool of potential impact factors. Journal of Cleaner Production, 175, 612-623.

Tam, C. M., Tam, V. W., \& Tsui, W. S. (2004). Green construction assessment for environmental management in the construction industry of Hong Kong. International Journal of Project Management, 22(7), 563-571.

USGBC (2018), U.S. Green Building Council Releases Annual Top 10 Conutries and Regions for LEED, Available at: https://bit.ly/32kYdeh [Access 9 July 2019].

USGBC (2019). Leadership in Energy and Environmental Design. Available at https://new.usgbc.org/leed. [Access 9 July 2019].

Vierra, S. (2014). Green building standards and certification systems. Green Building Standards and Certification Systems, 27.

Wang, J. Y., Kang, X. P., \& Wing-Yan Tam, V. (2008). An investigation of construction wastes: an empirical study in Shenzhen. Journal of Engineering, Design and Technology, 6(3), 227-236.

Wang, X., Yang, L., \& Ye, Y. (2019). Contention for urban state space and the rise of society in China: A case study of "Housing Planting" in Hohhot. Cities, 92, 219-229. Wu, P., \& Low, S. P. (2010). Project Management and Green Buildings: Lessons from the Rating Systems. Journal of Professional Issues in Engineering Education and Practice, 136(2), 64-70.

Wu, Z., Shen, L., Ann, T. W., \& Zhang, X. (2016). A comparative analysis of waste management requirements between five green building rating systems for new residential buildings. Journal of cleaner production, 112, 895-902.

Wu, Z., Yu, A.T.W., \& Shen, L. (2017). Investigating the determinants of contractor's construction and demolition waste management behavior in Mainland China. Waste Management, 60, 290-300.
Yang, L., Chau, K. W., Szeto, W. Y., Cui, X., \& Wang, X. (2020). Accessibility to transit, by transit, and property prices: Spatially varying relationships. Transportation Research Part D: Transport and Environment, 84, 102387

Wu, Z., Yu, A.T.W., \& Poon, C.S. (2019). An off-site snapshot methodology for estimating building construction waste composition - a case study of Hong Kong. Environmental Impact Assessment Review, 77, 128-135.

Yang, L., Zhou, J., Shyr, O. F., \& Huo, D. D. (2019). Does bus accessibility affect property prices? Cities, 84, 56-65.

Ye, G., Yuan, H., Shen, L., \& Wang, H. (2012). Simulating effects of management measures on the improvement of the environmental performance of construction waste management. Resources, conservation and recycling, 62, 56-63.

Yuan, H. (2013). A SWOT analysis of successful construction waste management. Journal of Cleaner Production, 39, 1-8.

Yüksel, I. (2012). Developing a multi-criteria decision making model for PESTEL analysis. International Journal of Business and Management, 7(24), 52.

Zhang, Y., \& Altan, H. (2011). A comparison of the occupant comfort in a conventional high-rise office block and a contemporary environmentally-concerned building. Building and Environment, 46(2), 535-545.

Zhang, Y., Kang, J., \& Jin, H. (2018). A review of green building development in China from the perspective of energy saving. Energies, 11(2), 334

Zheng, L., Wu, H., Zhang, H., Duan, H., Wang, J., Jiang, W., ... \& Song, Q. (2017). Characterizing the generation and flows of construction and demolition waste in China. Construction and Building Materials, $136,405-413$. 